\title{
IMPLEMENTASI FASILITAS HALTE TRANSJOGJA BERBASIS TEKNOLOGI SEBAGAI UPAYA PENINGKATAN KUALITAS PELAYANAN TRANSPORTASI DAERAH YOGYAKARTA
}

\author{
Muhammad Irfan Januar ${ }^{1}$, Gayuh Minang Lati ${ }^{1}$, Riza Rahma \\ Panduwiranita $^{1}$, Ratih Dianingtyas Kurnia ${ }^{1}$ \\ Program Studi Teknik Industri, Fakultas Teknologi Industri, Universitas \\ Islam Indonesia, Yogyakarta
}

\section{RINGKASAN}

TransJogja sebagai salah satu produk transportasi kota Jogja yang konon pada awal mulanya dibangun untuk menyediakan angkutan kota yang bersih, rapi, dan nyaman bagi siapa saja. Namun layanan transportasi ini masih tidak luput dari keluhan-keluhan penggunanya. Beberapa keluhan terhadap busway adalah dari segi waktu tunggu yang lama, jarak tempuh yang panjang, keselamatan dan keamanan, kenyamanan, sistem informasi yang kurang memadai, serta aksesibilitas halte yang dirasakan belum optimal (Kompas, 2011). Sistem informasi mengenai penjadwalan serta rute bus dirasakan belum optimal karena di dalam bus tidak terdapat peta rute bus begitu pula pada haltehalte busway itu sendiri, tidak seluruhnya memiliki display peta rute bus. Hal ini tentu dapat menyulitkan penumpang khususnya turis atau wisatawan dari luar kota Yogyakarta. Metode $5 \mathrm{~S}$ dapat diimplementasikan sebagai salah satu upaya untuk meningkatkan kualitas kerja dan lingkungan khususnya di area halte. Sistem informasi modern sederhana yang dapat diaplikasikan adalah dengan menggunakan konsep search engine menggunakan basis data dalam penyimpanan informasinya. Pengguna TransJogja akan lebih mudah dalam memperoleh informasi mengenai jalur bus yang digunakan dengan memperoleh peta sederhana berdasarkan asal dan tujuan halte. Kemudian perlunya meningkatkan kenyamanan dan keamanan bagi pengguna TransJogja yang akan menjadikan sistem yang lebih efektif dan ef sien bagi pengguna TransJogja pada umumnya dan bagi perusahaan yang menaunginya pada khususnya.

Kata kunci : Trans Jogja, Search Engine, 5S, Bus

PENDAHULUAN

\section{Latar Belakang}

Indonesia memiliki wilayah yang luas dari Sabang hingga Merauke, serta memiliki banyak pulau dan laut yang luas. Untuk pergi ke suatu 
tempat di Indonesia, selalu diperlukan informasi mengenai alat transportasi yang bisa digunakan untuk menuju suatu daerah tersebut. Transportasi darat di Indonesia merupakan sarana paling penting dalam memajukan perekonomian nasional. Jaringan lalu lintas darat terutama sepanjang pulau Jawa dan Sumatera memegang peranan yang sangat vital.

Transportasi darat di Indonesia merupakan sarana paling penting dalam memajukan perekonomian nasional. Kita melihat bahwa jaringan lalulintas darat terutama sepanjang pulau Jawa dan Sumatera memegang peranan yang sangat vital. Kota Jogja, kota yang sering disebut miniature Indonesia ini memiliki segudang keistimewaan. Mulai dari tata kelola pemerintahannya sampai ke banyak keistimewaan lainnya. TransJogja sebagai salah satu produk transportasi kota Jogja yang konon pada awal mulanya dibangun untuk menyediakan angkutan kota yang bersih, rapi, dan nyaman bagi siapa saja. Namun, Trans Jogja yang digembar gemborkan sebagai perbaikan moda layanan transportasi publik pada kenyataannya masih kurang optimal. Hal ini dikarenakan banyak factor, baik teknis maupun non teknis. Salah satu kendala yang dihadapi adalah jalur TransJogja masih menyatu dengan jalur publik, belum ada separasi atau pemisahan jalan. Hal ini tentu saja menjadi satu masalah tersendiri. Ketika terjadi bottle neck atau macet di beberapa ruas protocol kota Jogja di jam-jam sibuk seperti jam berangkat sekolah, TransJogja juga ikut mengalami kemacetan yang cukup panjang (Alkhasani, 2013). Sistem informasi mengenai penjadwalan serta rute bus dirasakan belum optimal karena di dalam bus tidak terdapat peta rute bus begitu pula pada halte-halte busway itu sendiri, tidak seluruhnya memiliki display peta rute bus. Hal ini tentu dapat menyulitkan penumpang khususnya turis atau wisatawan dari luar kota Yogyakarta.

Kemudian perbandingan dari trans jogja dengan yang lain antara lain pada situs resmi Trans Jakarta, di kanal paling ujung kiri dan kanan berisi rekaman CCTV halte-halte Trans Jakarta sehingga dapat dirasakan bermanfaat bagi pengguna untuk mengetahui kondisi di halte (Galuh, 2012). Kemudian dari pengguna angkutan umum di London, mayoritas stasiun di London memang terbilang besar dari segi ukuran. Namun, pengguna angkutan tidak bingung, termasuk mereka yang baru pertama kali masuk ke London. Penyebabnya ada dua, yaitu banyaknya informasi (di brosur gratis, di dinding, bahkan di lantai), serta selalu ada ada petugas tempat bertanya. Termasuk di stasiun sangat kecil yang cuma melayani 2 jalur tube sekali pun. Petugas ini ada di bagian ticket and assistance. Peta 
London dan jalur-jalur tube disediakan gratis di semua stasiun. Karena itu, hampir tiap waktu di tiap stasiun kita temui warga bule yang menekuri peta. Mereka biasanya warga luar London. (Indah Andarini, 2012)

\section{Tujuan Penulisan}

Tujuan dari pembuatan naskah PKM-GT yang bertemakan fasilitas transportasi ini antara lain adalah:

a. Meningkatkan layanan wisata dan perhubungan yang profesional.

b. Menimbulkan rasa aman dan nyaman dalam menggunakan jasa transportasi di Daerah Istimewa Yogyakarta.

c. Mengintegrasikan teknologi ke dalam sistem informasi layanan transportasi umum.

\section{Manfaat Penulisan}

Manfaat yang didapatkan dari adanya ide untuk meningkatkan fasilitas sistem informasi layanan transportasi umum ini antara lain :

a. Meningkatkan kenyamanan dalam menggunakan layanan transportasi umum.

b. Meningkatkan kemudahan akses informasi bagi pengguna jasa transportasi.

c. Meningkatkan mutu dan ef siensi serta kemudahan operasional.

\section{GAGASAN}

Kondisi Halte Busway TransJogja Saat Ini
Kondisi halte busway transJogja saat ini dinilai belum memadai. Beberapa keluhan penumpang terhadap busway adalah dari segi waktu tunggu yang lama, jarak tempuh yang panjang, keselamatan dan keamanan, kenyamanan, sistem informasi yang kurang memadai, serta aksesibilitas halte yang dirasakan belum optimal (Kompas, 2011).

Dari segi manajemen pengelolaannyamaupunkondisipengoperasiannya. Didukung dengan fasilitas di halte bus yang masih alakadarnya, kondisi ini menyebabkan kualitas pelayanan kepada masyarakat pengguna angkutan umum rendah, sehingga pada akhirnya mulai ditinggalkan oleh masyarakat. Berikut ini merupakan keadaan bus trans jogja saat ini dan data kinerja bis TransJogja menurut presentasi urban transport world asia 2012 di Jakarta adalah sebagai berikut:

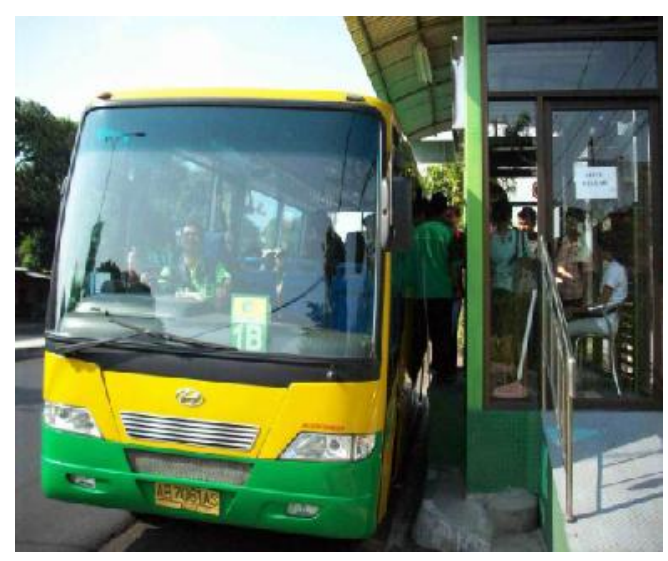

Gambar 1. Keadaan Halte Trans Jogja

Transportasi umum di Indonesia seperti bus TransJogja tergambar 
sebagai suatu ikon transportasi yang tidak aman dan kotor, selain itu manajemen dan system transportasi dan informasi yang kurang juga tidak memadai sebagai suatu transportasi umum yang sangat vital dan dibutuhkan oleh masyarakat Indonesia. Sistem informasi yang tidak memadai sangat menyulitkan bagi pengguna, terutama bagi pengguna jasa transportasi yang tidakmengenal area atau daerah tujuan yang dikehendakinya. Selain itu system keamanan yang kurang memadai juga menjadi gambaran rendahnya kualitas sarana transportasi Indonesia. Sejumlah persoalan yang mendera mulai dari manajemen yang amburadul hingga pelayanan kepada penumpang yang tidak layak, tidak juga kunjung teratasi. Untuk itulah perlu dilakukan peningkatan kualitas transportasi di Indonesia yang memudahkan manusia dan memberikan gambaran alat transportasi yang nyaman dan aman.

\section{Solusi yang pernah ditawarkan}

Penelitian ini bertujuan untuk menghasilkan Aplikasi Informasi Rute Bus TransJogja dan Informasi Wisata Kota Yogyakarta Berbasis J2ME yang mampu membantu pengguna untuk mendapatkan informasi seputar bus tranjogja dan informasi wisata kota Yogyakarta dengan efektif dan ef sien. Pada penelitian ini juga ditentukan tingkat kelayakan perangkat lunak yang telah dibuat.

Hasil penelitian menunjukkan bahwa Aplikasi Informasi Rute Bus TransJogja dan Informasi Wisata Kota Yogyakarta Berbasis J2ME ini mampu memberikan informasi kepada pengguna dengan efektif dan ef sien. Hasil pengujian dari segi functionality aplikasi ini memberikan hasil bahwa aplikasi telah berfungsi dengan baik, outpu yang keluar sesuai dengan input yang diberikan, sedangkan dari segi compatability aplikasi ini mampu berjalan pada semua handphone yang mendukung aplikasi java dengan konf gurasa MIDP 2.0 dan mempunyai tampilan yang maksimal pada resolusi minimal 240×320, dan dari segi usability aplikasi ini menunjukkan tingkat kelayakannya adalah layak. (Juni Susanto dan Adi Dewanto, 2012). Pada penelitian tersebut hanya mengacau perbaikan sistem informasi dari pelayanan TransJogja. Pada penelitian ini akan dibahas lebih luas, dan solusi yang diberikan pun lebih dari sekedar sistem informasi, namun tetap dibatasi bahwa yang diberikan solusi adalah hanya untuk keadaan halte TransJogja.

\section{Pihak yang Dapat Membantu Implementasi Gagasan}

Dalam pengembangan pelayanan fasilitas untuk kenyamanan dan keamanan konsumen dalam menggunakan transportasi umum melalui dukungan akses transportasi yang di usulkan ini dibutuhkan dukungan dan kerjasama dari beberapa pihak yaitu: 
Implementasi Fasilitas Halte....., Muhammad, Gayuh, Riza, Ratih

Pemerintah kota atau daerah, kan sebagai salah satu upaya untuk sebagai pihak yang nantinya dapat meningkatkan kualitas kerja dan memberikan penyuluhan sekaligus lingkungankhususnyadiareahalte. Hal promosi kepada masyarakat sekitar ini tentu dapat dipertimbangkan untuk dan para wisatawan terhadap peningkatak kualitas pelayanan. 5S transportasi pariwisata yang akan berasal dari lima huruf pertama istilah dicanangkan.

Dinas Pariwisata, adalah sebagai perantara dimana menjadi pihak yang akan membantu memasarkan dan menjual nama objek wisata yang ada.

Dinas Perhubungan adalah sebagai pihak yang membantu dalam pengadaan fasilitas untuk sarana transportasi yang diusulkan.

\section{Metode Gagasan}

Jepang untuk seiri (pemilahan), seiton (penataan), seiso (pembersihan), seiketsu (pemantapan), dan shitsuke (pembiasaan). Penerapan kelima sikap kerja ini dapat memberikan hasil yang lebih maksimal seperti mencegah kecelakaan, mengurangi waktu macet mesin (bottle neck) meningkatkan pengendalian operasional proses, dan menciptakan perusahaan yang lebih sehat (Osada, 2000).

Metode $5 S$ dapat diimplementasi-

\begin{tabular}{|c|c|}
\hline $5 \mathrm{~S}$ & Implementasi \\
\hline Seiri & $\begin{array}{l}\text { 1. Memilah barang-barang yang ada di area halte } \\
\text { 2. Menyisihkan barang-barang yang tidak diperlukan }\end{array}$ \\
\hline Seiton & $\begin{array}{l}\text { 1. Merapikan barang-barang yang ada di area halte } \\
\text { 2. Memberi garis blocking di area halte }\end{array}$ \\
\hline Seiso & $\begin{array}{l}\text { 1. Membersihkan area halte secara rutin } \\
\text { 2. Tanggung jawab individual dalam menjaga kebersihan }\end{array}$ \\
\hline Shiketsu & $\begin{array}{l}\text { 1. Pelabelan setiap peralatan dan zona-zona yang ada di } \\
\text { area halte }\end{array}$ \\
\hline Shitsuke & $\begin{array}{l}\text { 1. Penjadwalan } 5 \mathrm{~S} \text { rutin } \\
\text { 2. Manajemen ruangan } \\
\text { 3. Standard Operation Procedure }\end{array}$ \\
\hline
\end{tabular}

\section{Gambar 3. Implementasi 5S}

\section{Gagasan yang Diajukan}

Berdasarkan kondisi tempat sampah pada halte-halte yang halte belum menyediakan tempat sampah yang ada di Yogyakarta saat ini maka penulis mengusulkan untuk melengkapi fasilitas yang ada di halte tersebut dengan mengadakan dan search engine display dimana di dalam search engine tersebut terdapat fasilitas berupa tourism map, informasi mengenai tempat-tempat wisata di 
Yogyakarta, dan jalur bus TransJogja sehingga hal ini dapat memudahkan para wisatawan, para pendatang, dan juga para pengguna angkutan umum lainnya. Kemudian pada search engine sendiri menambahkan sebuah aplikasi untuk mencetak hasil dari apa yang para pengguna angkutan umum setelah melakukan searching lokasi-lokasi tujuan dan tempattempat wisata yang akan dikunjungi.
Kemudian ada juga mengenai sistem keamanan yang ditawarkan, kondisi halte yang butuh perluasan, dan juga sebuah pelayanan suara otomatis. Semua solusi itu ditawarkan dengan tujuan memberikan kenyamanan dan keamanan kepada para pengguna TransJogja.

Solusi fasilitas yang ditawarkan berupa:

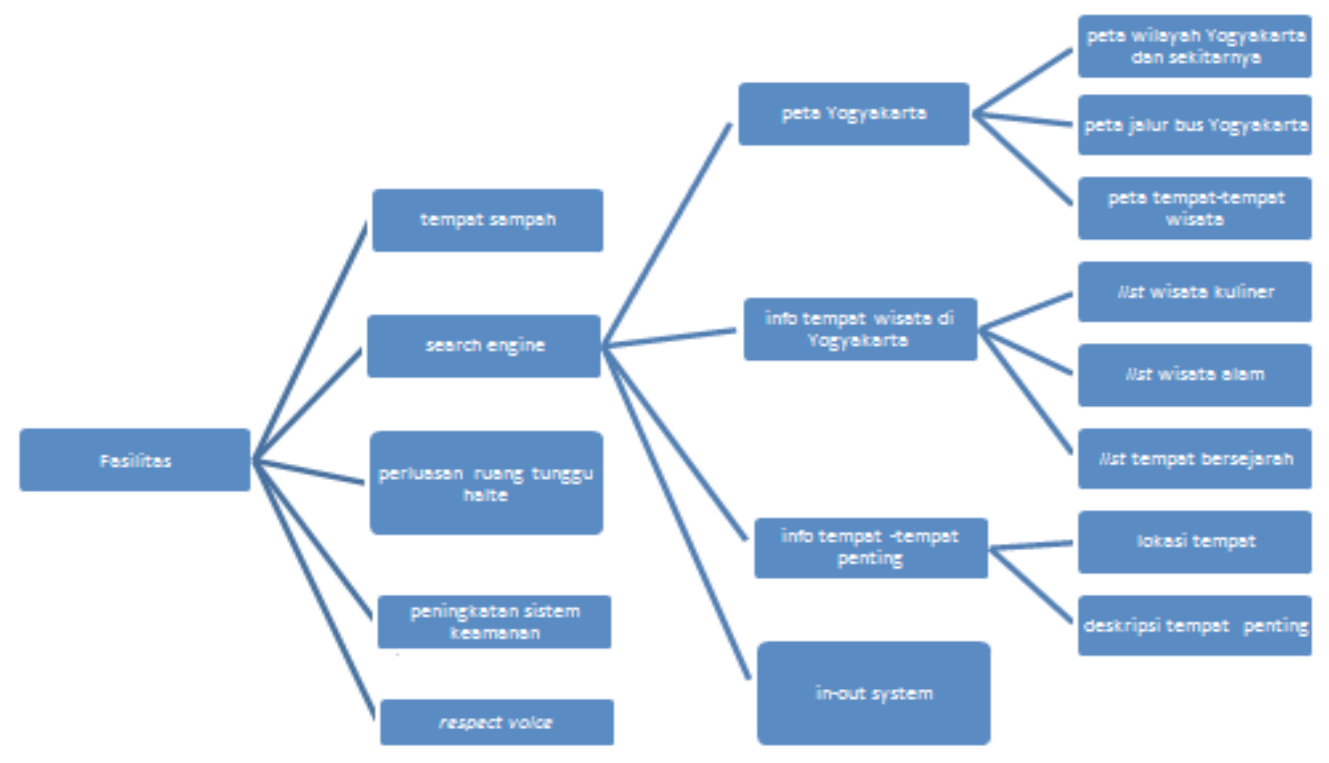

Gambar 4. Bagan Fasilitas Halte yang Ditawarkan

\section{Tempat Sampah}

Kegunaan dari tempat sampah disini adalah untuk memberikan suasana rapi dan indah serta nyaman untuk dipandang. Memberikankemudahan bagi para pengguna angkutan umum bagi menjaga kebersihan serta menumbuhkan kesadaran diri penumpang menciptakan lingkungan yang bersih.

\section{Search Engine}

Search Engine adalah suatu mesin untuk mencari informasi. Pada mesin yang digagas pada penelitian ini adalah mesin untuk mencari informasi tentang peta Yogyakarta, tempat wisata yang ada, serta tempat-tempat penting yang ada di Yogyakarta. Diberikan sebuah aplikasi untuk mencetak 
hasil searching dari pengguna angkutan umum. Hasil cetaknya adalah sebuah petunjuk perjalanan untuk pengguna angkutan umum yang ingin dia tuju. Fitur yang dapat ditawarkan dari search engine antara lain:

a. Peta Yogyakarta

- Peta wilayah Yogyakarta dan sekitarnya

- Peta jalur bus TransJogja

- Peta tempat-tempat wisata

b. TempatWisata

- List wisata kuliner

- List wisata alam

- List tempat-tempat bersejarah

c. Info Tempat Penting di Yogyakarta

- Lokasi tempat penting

- Deskripsi tempat penting

d. IN OUT SYSTEM

In Out System adalah sebuah system yang diberikan pada search engine. Sistem ini bertujuan agar informasi yang dicari oleh pengguna transjogja dapat dicetak hasilnya dengan aplikasi cetak yang ada dalam system ini.

\section{Perluasan Halte}

Kebutuhan perluasan halte bertujuan untuk membatasi kuota dari penumpang bis yang ingin naik, dimana perlu menerapkan system pembatasan kuota penumpang. Namun untuk itu dibutuhkan mengatasipenumpukanpenumpang di halte, perlu perluasan ruang tunggu di halte tersebut. Perluasan halte sendiri dapat memberikan kenyamanan bagi kaum difabel atau penyandang cacat dimana mereka membutuhkan ruang gerak yang lebih luas dalam bergerak. Dari perluasan halte ini juga perlu adanya saran tentang penambahan jumlah armada bis untuk menanggulangi penumpukan penumpang.

\section{Peningkatan Sistem Keamanan}

Seringnya terjadi tindakan criminal bagi pengguna angkutan umum menyebabkan kurangnya rasa aman dalam diri pengguna TransJogja. Tindakan criminal yang sering terjadi adalah yang secara tidak disadari oleh setiap orang. Maka dari itu dibutuhkan adanya peningkatan system keamanan di dalam halte bis agar setiap pengguna memiliki rasa aman dalam menggunakan jasa TransJogja. CCTV salah satu fasilitas yang diberikan untuk memantau setiap kejadian atau aktivitas di dalam setiap halte TransJogja. Kemudian, diberikan sensor keamanan pada pintu masuk halte TransJogja, berupa sensor senjata, obat terlarang, dan barangbarang yang membahayakan.

\section{Respect Voices}

Respect Voices adalah fasilitas yang diberikan untuk memberikan sesuatu yang berkesan bagi 
pengguna angkutan umum. Outputnya yaitu, ucapan terima kasih dan selamat datang untuk pengguna bis TransJogja. Diberikan sistem untuk sensor otomatis ketika penumpang naik ke atas bis maka penumpang akan mendengar suara "welcome to TransJogja". Lalu, untuk sensor otomatis ketika penumpang turun dari bis TransJogja, maka penumpang mendengar suara "thank you for use TransJogja". Dari solusi ini diharapkan akan menimbulkan rasa berkesan dalam hati setiap pengguna bis TransJogja dan meningkatkan peminat angkutan umum.

\section{KESIMPULAN}

Berdasarkan pembahasan dari gagasan-gagasan yang telah diberikan maka didapatkan kesimpulan sebagai berikut :

1. Perlu adanya perhatian khusus terhadap halte bus sebagai alat transportasi vital bagi calon penumpang khususnya kota Yogyakarta sebagai kota wisata .

2. Perbaikan yang perlu dilakukan yaitu dari segi kebersihan, keamanan, kenyamanan, dan fasilitas halte bus.

3. Dari segi kebersihan perlu adanya fasilitas tempat sampah yang memadahi guna menjaga kebersihan halte bus.

4. Dari segi fasilitas juga perlu adanya penambahan $f$ tur, yaitu search engine dimana mesin tersebut dapat memberi informasi peta tempat yang akan dituju dan info wisata yang dicari oleh pengunjung beserta alamat lengkap dan dapat dicetak, sehingga dapat memudahkan pengguna trans jogja.

5. Perlu dilakukan perluasan halte agar calon penumpang tidak banyak berdesakan dan mengurangi kemungkinan kriminalitas di halte bus.

6. Untuk mengurangi tindakan criminal di halte bus juga dapat dilakukan dengan menambahkan fasilitas CCTV agar segala kegiatan di halte dapat terekam sehingga dapat mengurangi kriminalitas dan dengan mudah dapat mengidentif kasi perilaku criminal jika terjadi kriminalitas di halte bus.

7. Perlu ditambahkan ftur respect voices, yaitu suatu system suara otomatis yang akan berbunyi jika penumpang naik atau turun bus, yaitu suara penyambutan selamat datang atau selamat jalan bagi calon penumpang yang akan menaiki bus.

\section{DAFTAR PUSTAKA}

Agus Minang. 2012. Presentasi Pelayanan Angkutan Umum URBAN TRANSPORT WORLD ASIA 31 Oktober 2012 Di Jakarta.

Juni Susanto, Adi Dewanto. 2012. Aplikasi Route Bus TransJogja dan Informasi Objek Wisata Di Kota Yogyakarta Berbasis J2ME. 
Implementasi Fasilitas Halte....., Muhammad, Gayuh, Riza, Ratih

Jurnal Elektronik Pendidikan Osada, Takashi M. 2000. Sikap Kerja

Teknik Informatika. Diakses pada tanggal 27 Februari 2013 dari 5S. Cetakan Ketiga. Jakarta: PPM.

http://journal.student.uny.ac.id/ Ngintip Halte TransJakarta diakses jurnal/artikel/628/54/174

Moda Transportasi Jogja diakses online pada 24 Februari 2013 http://alkhasanijawi3.blogspot. com/2012/08/moda-transportasijogja.html

Inilah Tujuh Keluhan Terhadap Busway diakses online pada 24 Februari 2013 http://lipsus.kompas.com/ topikpilihanlist/2133 pada 28 Februari 2013. http:// galoeh11.blogspot.com/2012/05/ ngintip-halte-transjakarta.html

Transportasi London 1 Angkut 10 Juta Penumpang Per Hari, diakses pada 28 februari 2013 http:// inspiringcikarang.wordpress. com/2012/11/25/transportasilondon-1/ 